\title{
The 10th International Chemical and Biological Engineering Conference (CHEMPOR 2008)
}

\author{
Eugénio C. Ferreira and Manuel Mota \\ Institute for Biotechnology and Bioengineering, Centre of Biological Engineering, University of Minho, 4710-057 Braga, Portugal \\ Correspondence should be addressed to Eugénio C. Ferreira, ecferreira@deb.uminho.pt
}

Received 25 March 2009; Accepted 25 March 2009

Copyright (C) 2009 E. C. Ferreira and M. Mota. This is an open access article distributed under the Creative Commons Attribution License, which permits unrestricted use, distribution, and reproduction in any medium, provided the original work is properly cited.

This special issue contains selected papers presented at the 10th International Chemical and Biological Engineering Conference (CHEMPOR 2008), held in Braga, Portugal, from the 4 th to the 6 th of September, 2008. The conference was jointly organized by the University of Minho, "Ordem dos Engenheiros," and the Institute for Biotechnology and Bioengineeing (IBB), with the support of "Sociedade Portuguesa de Química" and "Sociedade Portuguesa de Biotecnologia."

Thirty years elapsed since CHEMPOR was held at the University of Minho, organized by T. R. Bott, D. Allen, A. Bridgwater, J. J. B. Romero, L. J. S. Soares, and J. D. R. S. Pinheiro. Professors Bott, Soares, and Pinheiro made part of the Honor Committee and were present in this 10th edition. The opening ceremony conferred Professor Bott with a "Long Term Achievement" award acknowledging the important contribution that he brought along more than 30 years to the development of the chemical engineering science, to the launch of CHEMPOR series, and especially his cooperation with the University of Minho.

The CHEMPOR series traditionally brings together both young and established researchers and end users to discuss recent developments in different areas of chemical engineering. The scope of this edition was extended to biological engineering research. One of the major core areas of the conference program was life quality, due to the importance that chemical and biological engineering plays in this area. "Integration of Life Sciences \& Engineering" and "Sustainable Process-Product Development through Green Chemistry" were two of the leading themes with papers addressing such important issues. This was complemented with additional leading themes including
"Advancing the Chemical and Biological Engineering Fundamentals," "Multi-Scale and/or Multi-Disciplinary Approach to Process-Product Innovation," "Systematic Methods and Tools for Managing the Complexity," and "Educating Chemical and Biological Engineers for Coming Challenges." Papers selected for this special issue represent a good sample of the important themes that were addressed. We wish to thank the authors who have contributed to yield a high scientific standard to this special issue. We also extend our gratefulness to all reviewers through their dedicated efforts that have assisted us in this task.

This special issue contains six papers. Professor Bott's inaugural lecture entitled "Meeting the Challenge" constitutes the first paper. It addresses the importance of the challenge to the scientific community regarding food and water supply for a rapidly growing world population and consequently the need for the effective waste and energy management in processing operations, particularly in the effectiveness of heat recovery and the associated reduction in greenhouse gas emission from combustion processes.

In the second paper entitled "Biofouling Control in Cooling Water," Reg. Bott gives some examples of the effectiveness of different approaches to biofouling control by chemical or physical techniques or a combination of both, and the contribution to the control of greenhouse gas emissions. As stressed by Prof. Bott, unless suitable steps are taken, the accumulation of microbial deposits on the cooling water side of the steam condensers can reduce their efficiency and in consequence the overall efficiency of power production, with an inevitable increase in fuel consumption and hence in $\mathrm{CO}_{2}$ production. 
In the third paper, "Influence of Pyrolysis Parameters on the Performance of CMSM," Campo et al. aimed at understanding the influence of pyrolysis parameters-end temperature, quenching effect, and soaking time-on carbon hollow fiber membrane properties obtained by pyrolysis of a P84/S-PEEK blend. Permeation experiments were performed with nitrogen, helium, and carbon dioxide. Results demonstrated that the highest permeances were obtained for the membrane submitted to an end temperature of $750^{\circ} \mathrm{C}$ and the highest ideal selectivity for an end temperature of $700^{\circ} \mathrm{C}$. Furthermore, it was observed that the membranes quenched after reaching the end of the process revealed higher permeances than the ones naturally cooled.

In the fourth paper, "Influence of Different Cations of $\mathrm{N}_{3}$ Dyes on Their Photovoltaic Performance and Stability," Andrade et al. investigate the performance and stability of a $\mathrm{N}_{3}$ dye modified by substituting two of its protons by potassium or sodium cations. Dye-sensitized solar cells incorporating the new dyes were evaluated under light soaking $\left(1000 \mathrm{~W} \cdot \mathrm{m}^{-2}\right)$ at $50^{\circ} \mathrm{C}$. Photocurrent measurements demonstrated that proton substitution by potassium cations renders the system more stable. Further characterization of the potassium-based devices was performed by electrochemical impedance spectroscopy to investigate the charge transfer phenomena occurring at the different interfaces of the cells.

In the fifth paper is entitled "The kinetics of ampicillin release from hydroxyapatite for bones regeneration" by Ferreira et al. The aim of this work was to evaluate the application of hydroxyapatite as antibiotic delivery carrier. Adsorption kinetic models are compared to describe ampicillin release from hydroxyapatite, a material similar to real bones.

In the sixth paper entitled "Drop Distribution Determination in a Liquid-Liquid Dispersion by Image Processing," Brás et al. present the implementation of an image analysis technique for the automatic identification of drops with different sizes in monochromatic-digitized frames of a dispersion of toluene in water within a transparent mixing vessel. An algorithm is proposed for the calculation of drop size and shape distributions for modelling liquid-liquid systems.

Eugénio C. Ferreira Manuel Mota 

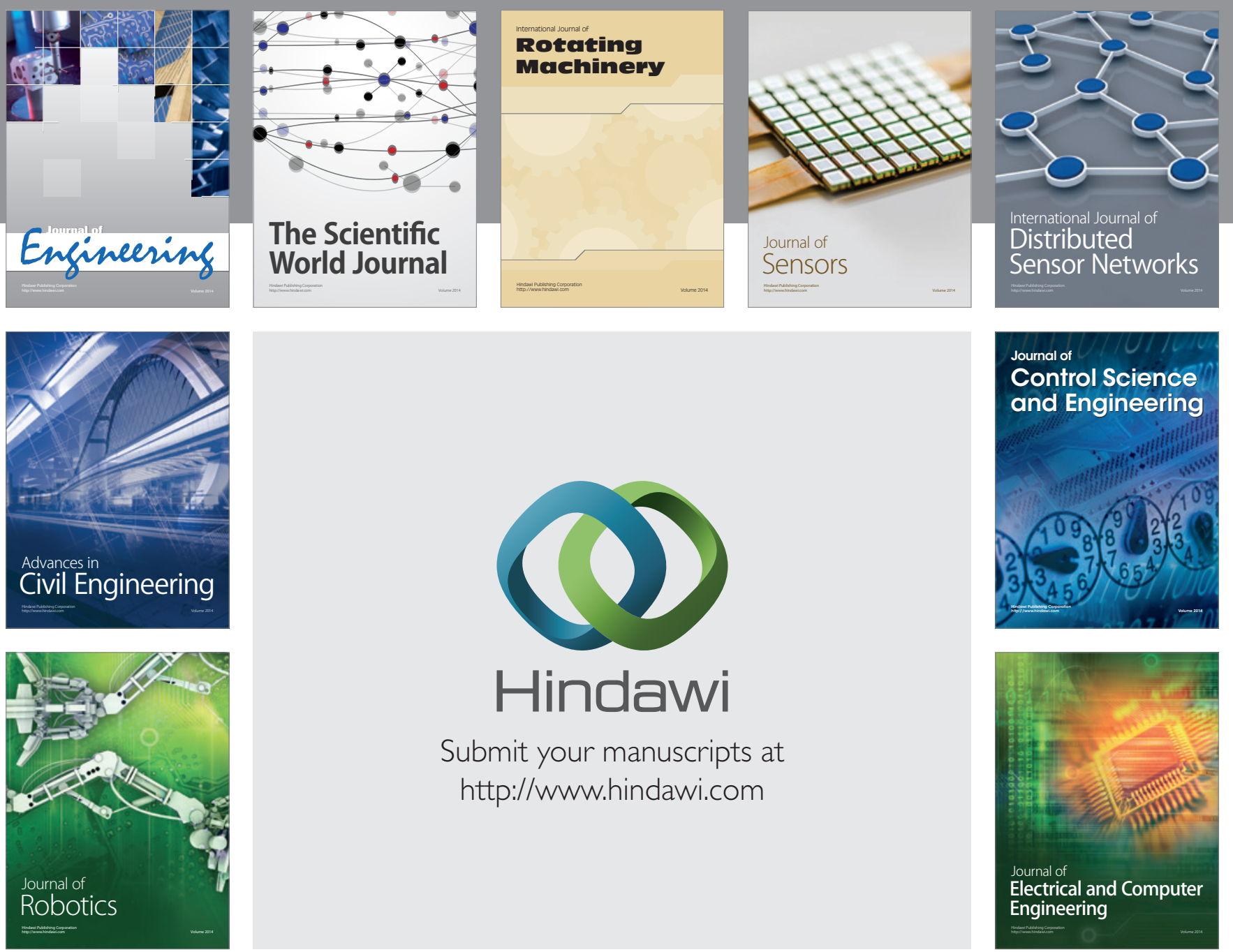

Submit your manuscripts at

http://www.hindawi.com
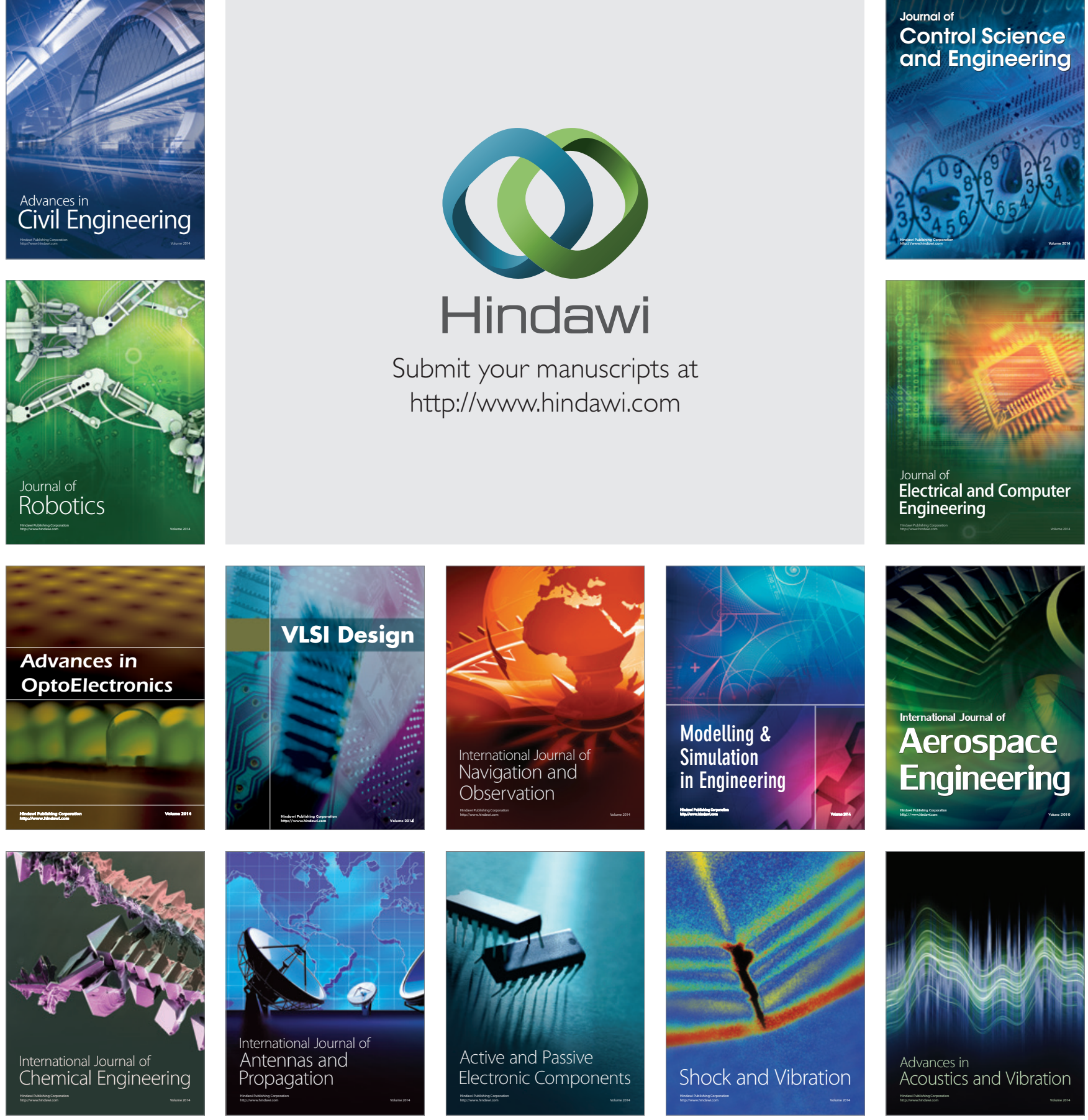